\title{
Evaluation of body composition and its relationship with physical fitness in professional soccer players at the beginning of pre-season \\ Evaluación de la composición corporal y su relación com la aptitud física em futebolistas professionales al inicio de la pré-temporada \\ *Diego Hilgemberg Figueiredo, *Diogo Hilgemberg Figueiredo, **Antonio Carlos Dourado, **Luiz Claudio \\ Reeberg Stanganelli, **Helcio Rossi Gonçalves \\ *State University of M aringá (Brazil), **StateU niversity of Londrina (Brazil)
}

\begin{abstract}
The aim of the study was to compare the players characteristics and physical fitness parameter saccording to playing positions and to identify the relation between body composition and physical fitness in professional soccer players at the beginning of the preparation period. Sixteen professional soccer players participated in this study. Body composition was evaluated by air displacement plethysmography instrumentation (BOD POD ${ }^{\circledR}$ ) and physical fitness with specific tests: RunningAnaerobic Sprint Test (RAST), Counter M oviment Jump (CMJ), Squat Jump (SJ) and Abalakov jump (ABK), Yo-yo Intermittent Recovery Level 1 (Yo-yo IR 1), agil ity test and flexibility. Kruskal Wall istest demonstrated no significant difference in all estimated body composition, age, height and physical fitness parameter saccording to three playing positions $(p<0.05)$. We verified a significant negative correlation between body fat percentage and the performance of CMJ, SJ, ABK, peak, mean and minimum power (-.51 to -.87) and a significant positive correlation with the agility parameter $(r=.85)$. Regarding to lean mass percentage, asignificant positive correlation wasfound with performance of $C M J, S J, A B K$ and peak, mean and minimum power (.51 to -.82) and significant negative correlation with agility parameter $(r=-.85)$. Based on the results, we concluded that at the beginning of a pre-season a higher body fat percentage is associated with a negative influence in physical fitness, thus confirming that a greater amount of lean mass percentage is positively associated with the initial level of physical fitness of professional soccer players.
\end{abstract}

Keywords: sports performance, physical fitness, body fat distribution, lean body mass distribution, team sports.

Resumén: El objetivo del studio fue comparar las características de los jugadores y los parâmetros de aptitud física según las posiciones de juego e identificar la relación entre la composición corporal y la aptitud física em futebolistas profisionales al inicio del período de preparación. Dieciséis futebolistas profesional es participaron em este estudio. La composición corporal se evaluómediante instrumentación de plestimografia por desplazamiento de aire (BOD POD ${ }^{\circledR}$ ) y aptitud física com pruebas específicas: capacidade anaeróbia (RAST), saltos verticales (CMJ, SJ y salto abalakov- ABK), resistência aeróbia, prueba de agilidade y flexibilidad. KruskalW all lis no demostró diferenciassignificativasem todos los parâmetros estimados de composición corporal, edad, al tura y condición física según las três posiciones de juego $(p<0.05)$. Verificamos uma correlación negativa significativa entre el porcentaje de grasa corporal y el rendimento de CMJ, S), ABK, potencia pico, media y mínima(-.51 to .87) y uma correlación positivasignificativa com el parâmetro de agil lidade $(r=.85)$. Em cuanto al porcentaje de massamagra, se encontro uma correlación positiva significativa com el rendimento de CMJ, S), ABK y potencia pico, media y mínima (.51 to - . 82) y correlación negativa significativa com el parâmetro de agilidade $(r=-.85)$. Com base em los resultados, concluimos que al inicio de una pré-temporada um mayor porcentaje de grassa corporal se associa com uma influencia negativa em la aptitud física, confirmando así que uma mayor porcentaje de massa magra se associa positivamente com el nível inicial de aptitud física de los futebolistas profesionales.

Palabras clave: rendimento desportivo, aptitud física, distribución de la grassa corporal, distribucíon de la massa corporal magra, deportes de equipo.

\section{Introduction}

Considered the soccer as an intermittent modality, with numerous actions of high intensity and short duration, researchers have been suggesting that the

Fecha recepción: 24-08-20. Fecha de aceptación: 20-10-20

Diego Hilgemberg Figueiredo

diegohilgemberg@ hotmail.com development of physical capacities (i.e., aerobic and anæerobic endurance), neuromuscular (i.e., strength, speed and power) and body composition are considered as essential aspects for the development of an optimal state, that could lead sport athletes do perform in a higher level (Di Salvo, Baron, Gonzalez-Haro, Pigozzi $\&$ Bachl, 2010; Stølen, Chamari, Castagna \& W isløff, 2005). Thus, sport athletes are led to improve their physical, technical-tactical and physiological attributes 
providing certain positive adaptations in the organism, aiming an increase in performance during the preparation process (pre-season), minimizing the risk of injury or excessive training (M eeusen, 2013).

Moreover, it is important to consider that in high performance sports settings like soccer, the pre-season can be relatively short in relation to the competitive period, which in turn becomes increasingly important to eval uate and monitor body composition and physical fitness parameters before the start of this period, in order to have a more complete evaluation of the initial state of the athletes. Thus, this information could be used to assist coaches and sport scientists to choose better strategies regarding to physical preparation to be applied leading therefore to improvements in performance, in order that athletes reach the competitive season in ideal conditions.

Thus, previous studies are routinely developed aiming to identify the relation between body composition and physical fitness, especially during preseason (Lago-Peñas, Casais, Dellal, Rey \& Domínguez, 2011; Stuempfle, Katch \& Petrie, 2003; Young \& Pryor, 2007). Young and Pryor (2007) found a positive relationship between body composition and fitness measures in under-18 Australian Rules Football players during a pre-season. The authors also demonstrated that selected players had significantly greater mass (i.e. muscle tissue), vertical jump, predicted maximum oxygen consumption $\left(\mathrm{VO}_{2 \max }\right)$, flexibility and were faster in $5 \mathrm{~m}, 20 \mathrm{~m}$ and agility test, which concluded that players with greater lean mass have an advantage for certain performance indicator which in turns may contribute to team success (Young $\&$ Pryor, 2007).

Lago-Peñas et al. (2011) shown that young soccer players belonging to successful teams with increased performance in soccer-specific skills like vertical jumps, and $20 \mathrm{~m}$ sprint, were that with increased lean mass and decreased body fat, demonstrating the association between body composition and physical fitness indicators. Despite the fact that physical fitness of soccer players before the beginning of a pre-season training have al ready been extensively studied, few studies have aimed to investigate the contribution and/ or relation between body composition and physical fitness variables at the beginning of the pre-season (Silvestre, West, Maresh \& Kraemier, 2006). This may contribute to a better understanding of the initial conditions of soccer playersand how it would influence physical fitness, which could be used by conditioning coaches to decrease the time needed during the pre-season aiming to increase performance.

Therefore, the aim of this study was to compare the players characteristics and physical fitness parameters according to playing positions, and to evaluate the relationship between body composition evaluated by airdisplacement plethysmography technique with physical fitness parametersin professional soccer playersobtained before the beginning of a pre-season training. Thus, considering that body composition of athletes might have a negative influence on performance outcomes (D oxey, Fairbanks, Housh, Johnson, Katch \& Lohman, 1987), the hypothesis of the present study is that at the beginning of the pre-season athletes with higher lean mass and lower adipose mass would have increasead physical fitness compared to athletes with lower lean mass and higher adipose mass.

\section{Material and method}

\section{Experimental overview}

The evaluations of the soccer players were performed in the first two days of the pre-season that started on February, 2019. All soccer players trained for more than 2 hrs per day for 4-5 times per week (excluding matches) during the previous season, which lasted 10 months (including pre-season and competitive season). In addition, all soccer players had a vacation break of 2 months ( 8 weeks) between the end of the previous season, and the beginning of the next one. $0 \mathrm{n}$ the first day, body composition (BODPOD ${ }^{\circledR}$ ), flexibility, vertical jump performance (CMJ, SJ, $A B K$ ) and the running anaerobic sprint test (RAST) were performed. On the second day, the Illinois agility and the yo-yo intermittent recovery level 1 (Yo-yo IR1) test were carried out. During each evaluation day a passive rest of 5 minutes were held between tests with a 24 hrs rest between the first and second day of evaluation. These tests were chosen since they are the most used during soccer players pre-season evaluation, being the athletes familiarized with these procedures before the study. In order to maintain the same experimental conditions in all tests, they were performed in the morning, without training sessions, under the supervision of experienced researchers with expertise in physical evaluations, being performed in the same pitch used for training sessions. All testing sessions were performed under similar climatic conditions (temperature: $25-29^{\circ} \mathrm{C}$ and relative humidity: 60-75\%). 


\section{Participants}

Sixteen elite male soccer league players (age: 23.3 \pm 3.6 years, height: $181.1 \pm 8.3 \mathrm{~cm}$ weight: $80.1 \pm$ $7.0 \mathrm{~kg}$ ) from a professional club volunteered to participate in this investigation. The sample size was not calculated a priori because it was selected by convenience. The power was calculated for the sample size, ranging from 0.80 to 0.89 , using Gpower 3.1 software (Dusseldorf, Germany). The club competed in a first division state level soccer league, which is considered the highest level of competition for regional teams and players. Playerswere divided into their tactical units for analysis (D efenders $n=6$, Midfielders $n=5$ and Forwards $n=5)$. To include the subject's data in the final analysis, the following requirements were adopted: a) completion the body composition measure; b) completion of $100 \%$ of performance assessment during the investigation period; c) not present injures during the investigation period. Subjects were informed that they were free to withdraw from the study at any time. All athletes were briefed about procedures and signed an informed consent form before participation. The study was approved by the local U niver sity's H uman Research Ethics Committee for Research involving Human (protocol number: 01985712.9.0000.5231).

\section{Body composition measure}

Body composition was assessed througth air displacement plethysmography (BOD POD ${ }^{\circledR}$ ), which is considered gold standard for body composition assessment. This technique assesses fat and lean mass percentage by measuring body volume using air displacement plethysmography. This system uses a single fiberglass structure that has two chambers separated via a fiberglass seat. The BOD POD ${ }^{\circledR}$ was calibrated before each test using a cal ibration method with volume of $50 \mathrm{~L}$ (manufacturer's calibration cylinder).

An important consideration for the application of air displacement plethysmography is the recognition of how air behaves when compressed under isothermal versus adiabatic conditions. Therefore, during testing it is important to account for the impact that clothing, hair, skin surface area, all make on the measurement of the test chamber volume. Subjects are tested wearing minimal clothing and a swim cap to compress the hair. A correction is made for surface area artifact that is computed-based on height and mass of the subject (Dempster \& Aitkens, 1995). A more comprehensive description of the basisfor the technology, system design, and the operating principles of the BOD POD ${ }^{\circledR}$ has been previously published (Dempster \& Aitkens, 1995).

\section{Physical fitness assessment}

Running anaerobic sprint test (RAST)

The RAST was applied with the participants performing six 35-m maximal sprints with a 10-second inter val between each sprint (Zacharogiannis, Paradidis $\&$ Tziortzis, 2004). The time for each run was measured by two photocells (CEFISE ${ }^{\circledR}$ standard photocells, Brazil) and the start for each sprint (10-second interval) occurred with a beep from the photocell equipment. The RAST variables evaluated were peak power (PP), mean (MP) and minimum power (MIP).

\section{Vertical jump performance}

To measure the vertical jump performance, players performed three jump tests: Counter Moviment Jump (CMJ), Squat Jump (SI) and Abalakov jump (ABK) according to the protocol described by Bosco, Luhtanen and Komi (1983). The CMJ is performed standing with straight legs and performing a jump beginning with a countermovement down to a knee angle of $90^{\circ}$ and hands on hips. The SJ was performed with a squat starting position, that is, knees flexed to $90^{\circ}$ and hands on hips. From this position, the participants made a maximal vertical jump landing with straight knees on themat. The ABK is performed standing upright, as still as possible on the mat with weight evenly distributed over both feet. W hen ready, the athlete squats down until the knees are bent at $90^{\circ}$ while swinging the arms back behind the body. W ithout pausing, the arms are swung forwards and theathletejumpsashigh as possible, landing back on themat on both feet at the same time. The take-off must be from both feet, with no initial steps or shuffling, and the subject must also not pause at the base of the squat. All jumpswere performed on a M ulti Sprint ${ }^{\circledR}$ contact platform, connected to the system for the Jump System jump measurement. Each player performed 3 maximal CMJ, SJ andABK inter spersed with a 1-minute rest between each jump. The best score was recorded in centimeters.

\section{Yo-yo intermittent recovery test level 1 (Yo-yo IR 1)}

The Yo-yo intermittent recovery test (Yo-Yo IR 1 ) consists of repeated $2 \times 20-\mathrm{m}$ runs back and forth between the starting, turning, and finishing lines at a progressively increasing speed controlled by áudio bleeps from a CD player (Bangsbo, laia \& K rustrup, 2008). After each 2 X 20 m running bout, the players were 
allowed a 10-second ( 2 X $5 \mathrm{~m}$ ) active recovery period. The test ended when the subjects failed twice to reach the starting line (objective evaluation) or the participant felt unable to complete another shuttle at dictated speed (subjective evaluation). Standard encouragements were provided to players throughout the test. All athletes were familiarized with the test and experimental proceduresbeforethestudy. TheVO ${ }_{2 \max }$ and total distance covered during the Yo-Yo IRI was considered as the testing score. The $\mathrm{VO}_{2 \max }$ was indirectly estimated through the test by the equation as follows: $\mathrm{VO}_{2 \max }=$ distance (meters) x $0.0084+36.4$ (Bangsbo, laia \& Krustrup, 2008).

\section{Agility test}

The Illinois agility test was used to assess agility performance. Test is set up with four cones forming the agility area (Figure 1). This test started lying face down with the hands at shoulder level, and the athlete sprints $9.20 \mathrm{~m}$, turns, and returns to the starting line. After returning to the starting line, he swerves in and out of four markers, completing two $9.20 \mathrm{~m}$ sprints to finish the agility course (Vescovi \& McGuigan, 2008). Performances were recorded using an electronic timing system (CEFISE ${ }^{\circledR}$ standard photocells, Brazil). Each player performed two maximal agility tests, interspersed with two minutes rest between each test. The best performance was recorded in seconds.

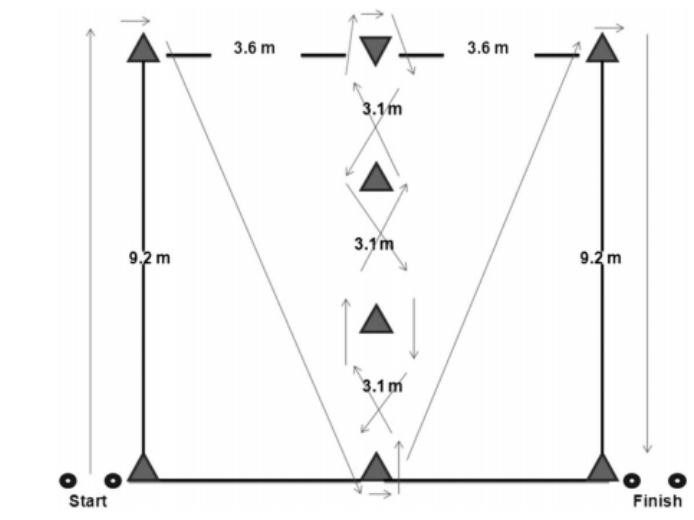

Figure 1. Schematic representation of the Illinois change of direction speed test.

Flexibility

Flexibility was measured using the Wells Bank. This test consists of checking the flexibility of the trunk and hamstring muscles. The measures were carried out three times, adopting the highest value in centimeters (Mikkelsson, N upponen, Kaprio, Kautiainen, Mikkelsson \& Kujala, 2006).

\section{Statistical analyses}

All statistical procedureswere performed using SPSS
20.0 software (v.20, SPSS Inc., Chicago, IL, USA). Data are expressed as median \pm interquartile range. The Shapiro-W ilk test was used for data normality. The Kruskal Wallis test was used to compare players characteristics and physical fitness parameters according to playing positions. The relationship between body composition and physical fitness was analyzed using the Spearman correlation. The thresholds used for quantitative assessment were as follow: trivial $(<0.1)$, small $(<0.3)$, moderate (0.3-0.5), large (0.5-0.7), very large (0.7-0.9), nearly perfect $(>0.9)$, perfect (1.0) (Hopkins, Marshall, Batterham \& Hanin, 2009). In addition, Cohen's effect size (ES) was calculated to evaluate the magnitude of changes (Cohen, 1988). ES were interpreted asfollows: $<0.2$ trivial; 0.2-0.6, small; 0.6-1.2, moderate; 1.2-2.0, large; 2.0-4.0, very large (Hopkins, et al., 2009). The level of significance set was as $p>.05$

\section{Results}

Table 1 present the mean values and standard deviation of players characteristics evaluated according to three playing positions. Kruskal Wallis test demonstrated no significant difference for body composition, age and height variables evaluated according to playing positions ( $p>.05)$.

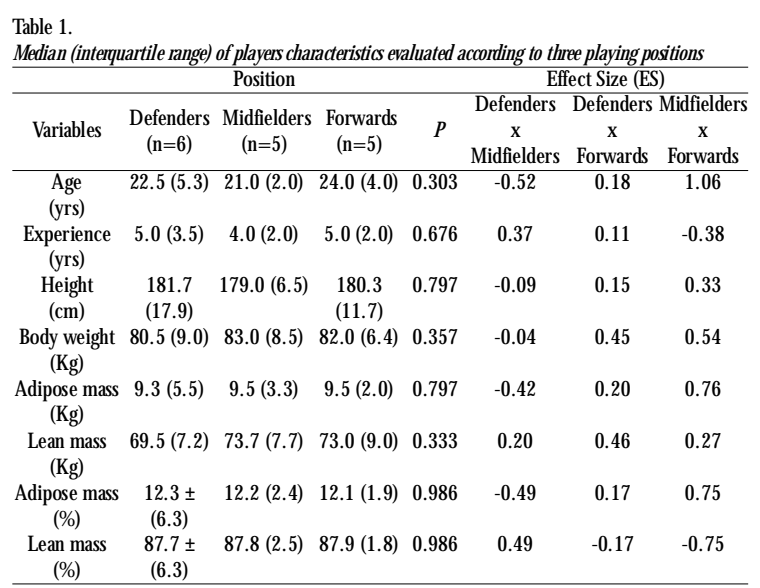

The mean values ( \pm SD) of physical fitness parameters distributed within playing positions are presented in Table 2. No differences were observed in $\mathrm{VO}_{2 \text { max }}$ distance, agility, CMJ, SJ, ABK, flexibility, peak power, mean power and minimum power between positions $(p>$.05).

Considering the values of body composition and physical fitness evaluated, correlations were performed in an attempt to identify the possible relation between components of body composition, regarding to body fat 
Table 2 .

Median (interquartile range) of physical fitness parameters evaluated according to three playing positions

\begin{tabular}{|c|c|c|c|c|c|c|c|}
\hline \multicolumn{5}{|c|}{ 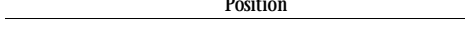 } & \\
\hline Variables & $\begin{array}{l}\text { Defender } \\
\quad(n=6)\end{array}$ & $\begin{array}{l}\text { Midfiel der } \\
\quad(n=5)\end{array}$ & $\begin{array}{l}\text { Forward } \\
(n=5)\end{array}$ & $p$ & $\begin{array}{c}\text { Defenders } \\
x \\
\text { Midfielders }\end{array}$ & $\begin{array}{c}\text { Defenders } \\
x \\
\text { Forwards }\end{array}$ & $\begin{array}{c}\text { Midfielders } \\
x \\
\text { Forwards }\end{array}$ \\
\hline $\begin{array}{c}\mathrm{VO}_{2 m \max ^{-1}} \\
\left(\mathrm{ml} \cdot \mathrm{kg} \cdot \mathrm{min}^{-1}\right)\end{array}$ & $47.7(4.7)$ & $49.2(2.0)$ & $47.6(1.0)$ & 0.463 & 0.41 & -1.14 & -1.99 \\
\hline $\begin{array}{l}\text { Distance } \\
\text { (m) }\end{array}$ & $1340(560)$ & ) $1520(240)$ & 1344 (120) & 0.463 & 0.40 & -1.15 & -2.01 \\
\hline $\begin{array}{l}\text { Agility } \\
\text { (s) }\end{array}$ & $15.2(3.1)$ & $14.0(2.1)$ & $15.2(1.5)$ & 0.409 & -0.48 & 0.16 & 0.76 \\
\hline $\begin{array}{l}\text { CMJ } \\
(\mathrm{cm})\end{array}$ & $36.9(4.0)$ & $37.2(3.2)$ & $36.0(4.4)$ & 0.747 & 0.39 & -0.47 & -0.77 \\
\hline $\begin{array}{l}\text { SJ } \\
(\mathrm{cm})\end{array}$ & $33.8(8.8)$ & $34.6(8.2)$ & $32.6(8.0)$ & 0.672 & 0.26 & -0.64 & $-0,82$ \\
\hline $\begin{array}{l}\text { ABK } \\
(\mathrm{cm})\end{array}$ & $42.9(6.0)$ & $44.6(6.1)$ & $42.9(7.7)$ & 0.649 & 0.83 & 0.60 & $-0,17$ \\
\hline $\begin{array}{l}\text { Flexibility } \\
(\mathrm{cm})\end{array}$ & $35.5(4.8)$ & $35.5(6.0)$ & $38.0(5.0)$ & 0.525 & -0.74 & 0.17 & 0,77 \\
\hline $\begin{array}{c}P P \\
\left(W \cdot \mathrm{kg}^{1}\right)\end{array}$ & $11.1(1.8)$ & $12.2(2.7)$ & $10.8(3.0)$ & 0.831 & 0.24 & -0.22 & $-0,43$ \\
\hline $\begin{array}{c}\mathrm{MPI} \\
\left(\mathrm{W} . \mathrm{kg}^{1}\right)\end{array}$ & $7.1(1.7)$ & $8.0(1.4)$ & $6.7(1.4)$ & 0.817 & 0.08 & -0.32 & -0.53 \\
\hline $\begin{array}{c}M P \\
\left(W . \mathrm{kg}^{1}\right)\end{array}$ & $10.0(3.2)$ & $10.2(1.6)$ & $9.2(2.5)$ & 0.946 & 0.17 & -0.22 & -0.40 \\
\hline
\end{tabular}

and lean mass percentage and parameters of physical fitness. N egative correlations ranging from -.51 to -.87 were found between body fat percentage and performance of $S \mathrm{~J}(p=.0001), \mathrm{CMJ}(p=.011), \mathrm{ABA}(p$ $=.03)$, peak power $(p=.003)$, mean power $(p=.002)$ and minimum power $(p=.001)$. In addition, positive correlation was found between body fat percentage and agility ( $r=.85 ; p>.001)$, However, trivial and small correlation was found between body fat percentage and flexibility $(r=.06), V 0_{2 \max }(r=-.18)$ and distance covered $(r=-.18)$ (Figure 2).

Correlations between lean mass percentage and physical fitness are shown in figure 3. Large and very large correlation ranging from 0.51 to 0.82 were found between lean mass and performance in $S J(p=.001)$, $\operatorname{CMJ}(p=.001), \operatorname{ABA}(p=.03)$, peak power $(p=.03)$,
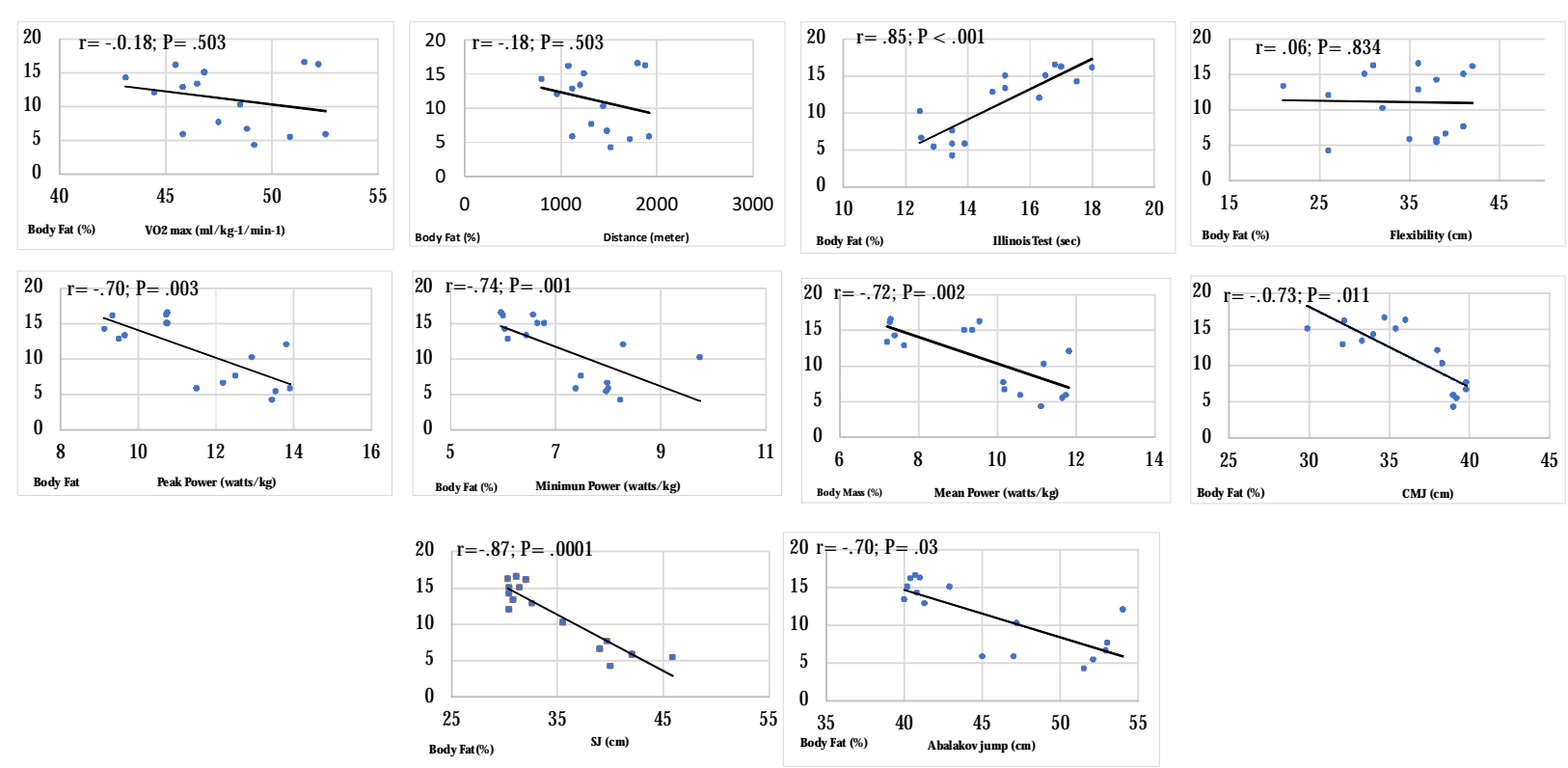

Figure 2. Correlation between body fat percentage and physical fitness measures eval uated for all players
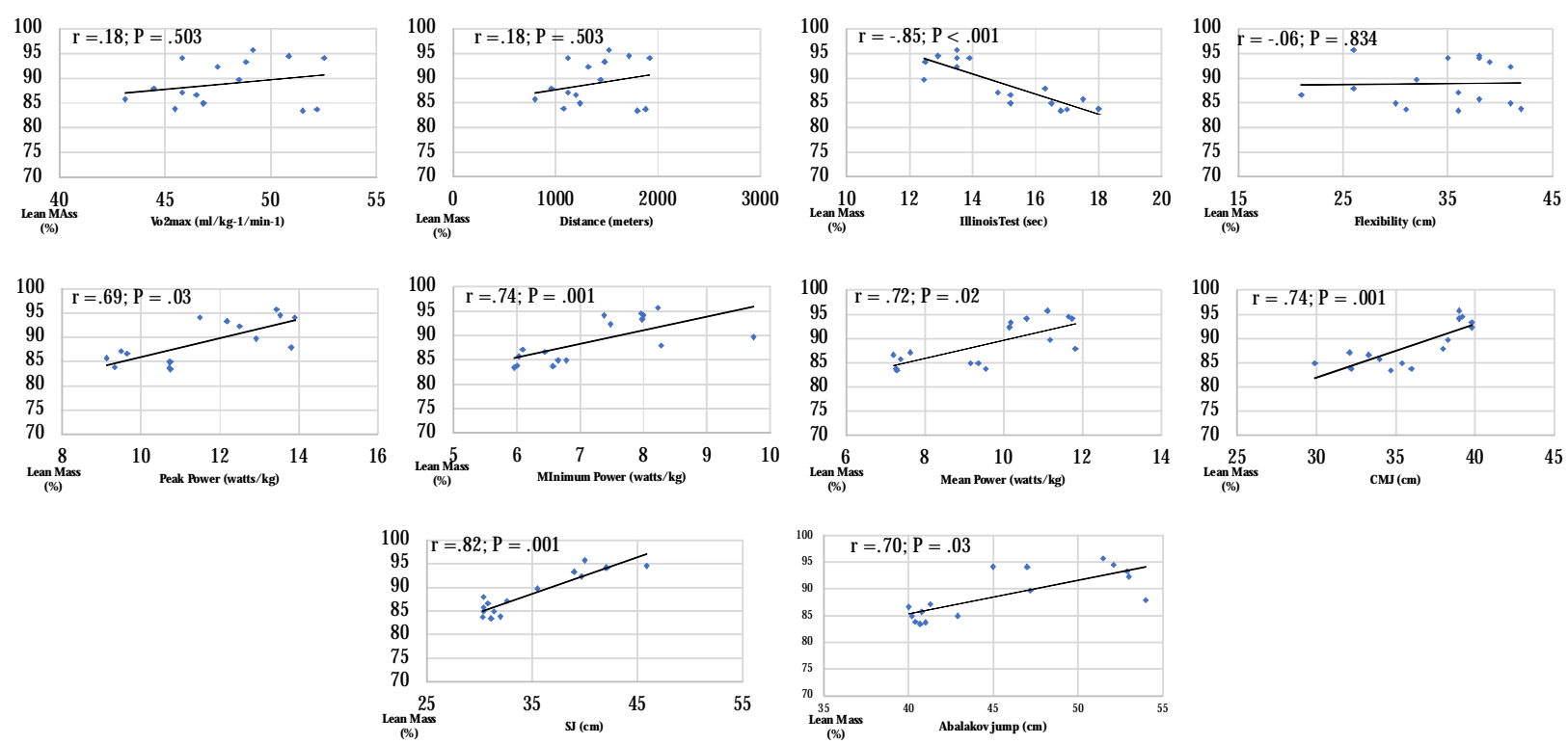

Figure 3. Correlation between lean mass percentage and physical fitness measures eval uated for all players 
mean power $(p=.02)$ and minimum power $(p=.001)$. In addition, very large negative correlation was found between lean mass percentage and agility $(r=-.85)$. There was a trivial and small correlation between lean mass percentage with flexibility $(r=-.06), V_{2}(r=$ .18) and distance covered $(r=.18)$.

\section{Discussion}

The present study aimed to eval uate the relationship between body composition variables and physical fitness measures of professional soccer players at the beginning of their preparation for the main national competitions. The main findings of our study were the significant negative correlations between body fat percentage with vertical jumps, peak, mean and minimum power and a significant positive correlation with the agility parameter. There was a large and very large positive relation between lean mass percentage and the variables: vertical jumps, peak, mean and minimum power and significant negative correlation with agility, confirming partially the initial hypothesis. Additionally, no differences were observed in all estimated body composition, age, height and physical fitness parameters between the players positions.

Soccer is a team sport, that involves many players, which requires an efficient collective organization and, simultaneously, the specific development of each player based on the individual and group perspective. Thus, positional differences are commonly cited within the literature. Different of our study, Carling and O rhant (2010) observed significant differences among playing position with regards to body fat percentage and fatfree mass during a pre-season in professional soccer players, being the midfielders the players with the highest values of body fat percentage when compared to the other playing positions.

In the present investigation, we found negative correlations between body fat percentage and performance parameters at the begninig of the preseason, which clearly demonstrated that body composition has a great impact on performance. 0 stojic (2003) found that body fat percentage is higher in professional soccer players during the start of the season which decreased during the season. In addition, the authors also found that the main improvements in sprint time during the season were related with a reduction in body fat percentage. Prevoius studies have demonstrated the detrimental effect of detraining on body composition and performance parametersin soccer players (J00, 2018; Koundourakis, Androulakis, Malliaraki, Tsatsanis, Venihaki \& Margioris, 2014). Koundourakis et al. (2014), observed that a detraininig period of six weeks significantly increased body weigth and body fat percentage and reduced performance in professional soccer players.

The soccer players of the present investigation were evaluated 8 weeks after the end of the competitive season, which might have had some influence on their body composition and performace, even though any evaluation was held at the end of the competition season to confirm these results. However, the present investigation suggests that soccer players that return to a pre-season with lower body fat percentage and higher lean mass start the pre-season in better conditions when considering the performance level, which might imply in a short time to increase performance levels when compared to soccer players that return to pre-season with higher fat percentage and lower lean mass. Thus, better training strategies might be employed during breaks at the end of the competitive season to maintain body composition in optimal ranges in order that soccer players could start the pre-season in better physical conditions.

In order to develop muscular strength and athletic performance, vertical jump height seems to be a determinant variable for sportssuccess (K raska, Ramsey, $H$ aff, Fethle, Sands, Stone \& Stone, 2012). The findings of the present study for vertical jumps are similar to those presented by Silvestre, West, Maresh and Kraemier (2006) in college soccer players who were tested at the beginning of a season, which found that higher body fat and lean mass percentage were associated with lower and higher vertical jumps respectively, which means that soccer players with higher lean mass percentage are those who will perform better in the vertical jump, since muscle mass can contribute as decisively as the percentage of fat to improve performance (Silvestre, et al., 2006).

O ne of the factors that can lead to increase vertical jump height is body mass. That is, the higher the body mass an athlete has, the greater the need to generate power to perform the jump at the same height compared to an athlete with less body mass (Roschel, et al., 2009). Kraska et al. (2012) stated that athletes considered to be more explosive and stronger are those with a higher jump. Thus, an athlete who has a lower body fat percentage will be the one that can generate more height for the vertical jump (Davis, Briscoe, M arkowski, Saville\&Taylor, 2003), what wasidentified in the present 
study. Considering these differences between athletes, some use for their jumping actions more strength compared to others who use more explosion for their execution (Earp, et al., 2010).

O ur results showed that the body fat percentage had positive and significant impacts in relation to agility. Aurélio et al. (2016) investigated the relation between body composition, anthropometry and physical fitness in U-12 playersaccording to their playing positions. Their results indicate a positive and significant correlation between the body fat percentage and the agility test in the forwards players. However, they found a negative and significant correlation between the increases in body fat percentage and the decreases in agility test in the soccer defenders. More recently, Ceballos-Gurrola, Bernal-Reyes, Jardón-Rosas, Enríqeuz-Reyna, DurazoQ uiroz and Ramírez-Siqueiros (2021) found that body composition havean influence in physical fitness of soccer players, more specifically a higher body fat percentage was related to lower agility on the same test used in the present investigation (i.e., Illinois change of direction speed test), which further demonstrated that higher amounts of body fat percentage during the beginning of the pre-season might disrupt tasks that require speed as main actions.

Considering the findings of the present study and the aforementioned, we can consider that agility is a variable that probably depends on the coordinative aspects related to performance (Sheppard \& Young, 2006). Therefore, it is possible that individuals with higher body fat percentage values have difficulty moving faster in acceleration and deceleration movements imposed by the test itself, which is considered as an important aspect of soccer success during matches.

N onetheless, another factor that is affected by body composition is aerobic performance (Ramana, Surya, Sudhakar \& Balakrishna, 2004). Different from the present study, Silvestre et al. (2006), found a significant negative correlation between body fat percentage and $\mathrm{VO}_{2 \max }$ and a positive correlation between lean mass percentage and $\mathrm{VO}_{2 \max }$ in collegiate soccer players.

Moreover, Maciejczyk, W iecek, Szymura, Szygula, W iecha and Cempla (2014) in a study that aimed to determine the influence of body composition and the increase in body mass on aerobic performance, found negative correlations between $\mathrm{VO}_{2 \max }$ with body mass and body fat percentage.

In addition, the author demonstrated no statistically significant correlation between $\mathrm{VO}_{2 \text { max }}$ and absolute lean mas. A negative correlation found between these variables demonstrated that regardless of high body mass being the result of an increase body fat percentage or an elevated lean mass percentage, the values of $\mathrm{VO}_{2 \max }$ were decreased, representing a lower aerobic performance (Welsman, Armstrong, Nevill, W inter \& Kirby, 1996). Previous studies have shown that once a higher level of training has been achieved, the $\mathrm{VO}_{2 \max }$ in elite athletes becomes a less sensitive variable to detect changes in performance (Franks, W illiams, Reilly \& Nevill, 1999), which could explain in the present study any significant correlation between body fat and lean mass percentage and $\mathrm{VO}_{2 \max }$

The limitations of this study were the use of a field test to determine zerobic performance. However, the test used in the present study may provide more ecological validity for soccer players. In addition, the small sample size evaluated in the current investigation could be considered a limitation. Since the body composition and the performance variables were only measured before the beginning of the pre-season, this approach must be conducted during the end of the preseason or during the in season in future research to describe trends in body composition and performance variables among professional soccer players.

\section{Conclusion}

According to the results of the present study, it seems that soccer players start the preseason with the same levels of body composition and performance, regardless of the position. The major findings of this study show that soccer players with less body fat and increased lean mass percentage before the initial of a pre-season presents an advantage for certain physical fitness indicators. In addition, there was no significant association between initial body fat and lean mass percentage during pre-season with flexibility, $\mathrm{VO}_{2 \max }$ and distance covered.

0 verall, this analysis suggests that the evaluation and monitoring of the initial values of body composition before the pre-season is important to track individual differences in physical fitness of soccer players.

\section{Acknowledgements}

The authors would like to thank all the participants of this research for their valuable time and contribution.

\section{References}

Aurelio, J., Dias, E., Soares, T, Jorge, G., Espada, M. A. 
C., Filho, D. M. P., Pereira, P., \& Figueiredo,T. (2016). Relationship between Body Composition, Anthropometry and Physical Fitness in Under-12 Soccer Players of Different Positions. Int I Sports Sci, 6(1A), 25-30.

Bangsbo, J. , laia, F. M. , \& K rustrup, P. (2008). TheYo-yo intermittent recovery test: a useful tool for evaluation of physical performance in intermittent sports. Sports M ed, 38(1). 37-51. doi: 10.2165/ 00007256-200838010-00004.

Bosco, C. , Luhtanen P., \& Komi, P. (1983). A simple method for measurement of mechanical power in jumping. Eur J Appl Physiol, 50: 273-282.

Carling, C., \& O hhant, E. (2010). Variation in body composition in professional soccer players: interseasonal and intraseasonal changesand the effects of exposure time and player position. J Strength Cond Res, 24(5), 1332-9.

Ceballos-Gurrola, 0., Bernal-Reyes, F., Jardón-Rosas, M., Enríquez-Reyna, M. C., Durazo-Quiroz, J., \& Ramírez-Siqueiros, M. G. (2021). Body composition and physical performance of college soccer by player's position. Retos N uevas tendencias en Educacion Física, Deportey Recreacíon, (39) 52-57.

Cohen, J. (1988). Statistical Power Analysis for Behavioral Sciences (2nd ed.). Hillsdale, NJ, USA: Erlbaum Associates

Davis, D. S., Briscoe, D. A., Markowski, C. T., Saville, S. E. \& Taylor, C. J. (2003). Physical Characteristics that Predict Vertical Jump Performance in Recreational MaleAthletes. PhysTher Sport, 4(4), 16774.

Dempster, P., \& Aitkens, S. (1995). A new air displacement method for the determination of human body composition. Med Sci Sports Exerc, 27(12), 1692-1697.

Di Salvo, V., Baron, R., Gonzalez-Haro, C., Gormasz, C. , Pigozzi, F. \& Bachl, N. (2010). Sprinting analysis of elite soccer players during European Champions League and UEFA Cup matches. I Sports Sci, $28(14), 1489-1494$ doi: $10.1080 /$ 02640414.2010 .521166 .

Doxey, G. E., Fairbanks, B., Housh, T. J., Johnson, G. O., Katch, F., \& Lohman,T. (1987). Roundtable: Body composition - Part 1: Scientific considerations. $N$ atl Str Cond Assoc, 9, 12-6.

Earp. J. E., Kräemer, W. J., N ewton, R. U., Comstock, B. A., Fragala, M. S., Dunn-Lewis, C., SolomonHill, G., Penwell, Z. R., Powell, M. D., Volek, J. S., Denegar, C. R., Hakkinen, K., \& Maresh, C. M.
(2010). Lower-Body Muscle Structure and Its Role in Jump Performance During Squat, Countermovement, and Depth Drop Jumps. I Strength Cond Res, 24(3), 722-29. doi:10.1519/ JSC.0b013e3181d32c04.

Franks, A. M., W illiams, A. M., Reilly, T., \& N evill, A. (1999). Talent identification in elite youth soccer players: Physical and physiological characteristics. Communication to the 4th World Congress on Science and Football, Sydney. J Sports Sci, 17,812.

Hopkins, W. G., Marshall, S. W., Batterham, A. M., \& Hanin, J. (2009). Progressive statistics for studies in sports medicine and exercise science. M ed Sci Sports Exerc, 41(1),3-13. doi: 10.1249/ MSS.0b013e31818cb278.

J00, C. H. (2018). The effects of short term detraining and retraining on physical fitness in elite soccer players. Plos One, 13(5), e0196212. doi: 10.1371/ journal. pone. 0196212.

Koundourakis, N. E., Androulakis, N. E., Malliaraki, N., Tsatsanis, C., Venihaki, M., \& Margioris, A. N. Discrepancy between exercise performance, body composition, and sex steroid response after a sixweek detraining period in professional soccer players. Plos One, 9(2), e87803. Doi: 10.1371/ journal. pone. 0087803.

Kraska, J. M., Ramsey, M. W., Haff, G. G. , Fethle, N., Sands, W. A., Stone, M. E. \& Stone, M. H. (2009). Relationship Between Strength Characteristics and Unweighted and Weighted Vertical Jump Height. Int SportsPhysiol Perform, 4(4), 461-73. doi: 10.1123/ ijspp.4.4.461.

Lago-Peñas, C., Casais, L., Dellal, A., Rey, E., \& Domínguez, E. (2011). Anthropometric and physiological characteristics of Young soccer players according to their playing positions: relevance for competition success. I Strength Cond Res, 25(12), 33583367. doi: 10.1516/ JSC.0b013e318216305d.

Maciejczyk, M., W iecek, M., Szymura, J., Szygula, Z., W iecha, S., \& Cempla, J. (2014). The Influence of Increased Body Fator Lean Body Mass on Aerobic Performance. Plos One, 9(4),1-6. doi: 10.1371/ journal. pone. 0095797.

M eeusen, R. (2013). Prevention, diagnosis, and treatment of the overtraining syndrome: joint consensus statement of the European College of Sport Science and the American College of Sports Medicine. M ed Sci Sports Exerc, 45(1), 186-205.

Mikkelsson, L. O., N upponen, H., Kaprio, J., Kautiainen, H., Mikkelsson, M., \& Kujala, U. M. (2006). 
Adolescent flexibility, endurance strength, and physical activity as predictors of adult tension neck, low back pain, and knee injury: a 25 year follow up study. Br J Sports M ed, 40(2):107-13. doi: 10.1136/ bjsm.2004.017350.

Ostojic, S.M. (2003). Seasonal alterations in body composition and sprint performance of elite soccer players. Journal of Exercise Physiology online, 6(3),2427.

Ramana, Y. V., Surya, M. V. L. K., Sudhakar, S. R., \& Balakrishna, N. (2004). Effect of changes in body composition profile on $\mathrm{VO}_{2}$ max and maximal work performance in athletes. J Exerc Physiol, 7(1),34-9.

Roschel, H., Batista, M., M onteiro, R., Bertuzzi, R. C., Barroso, R., Loturco, I., Ugrinowitsch, C., Tricoli, V. \& Franchini, E. (2009) Association Between Neuromuscular Tests and Kumite Performance on the Brazilian Karate N ational Team. J Sports Sci M ed, 8(3),20-4.

Sheppard, J., \& Young, W. (2006). A gility literature review: Classifications, training and testing. I Sports Sci, $24(9), 919-32$. doi: $10.1080 /$ 02640410500457109.

Silvestre, R., West, C., Maresh, C. M., \& Kraemier, W. J. (2006). Body composition and physical performance in men's soccer: a study of a national collegiate athletic association division 1 team. J
Strength Cond Res 20(1), 177-183. doi: 10.1519/ R17715.1.

Stølen, T., Chamari, K., Castagna, C., \& W isløff, U. (2005). Physiology of Soccer. Sports M ed, 35 (6), 501536.

Stuempfle, K. J., Katch, F. I., \& Petrie, D. F. (2003). Body composition relates poorly to performance tests in NCAA Division III football players. I Strength Cond Res 17 (2), 238-244.

Vescovi, J. D., \& M cGuigan, M. R. (2008). Relationships between sprinting, agility, and jump ability in female athletes. J Sports Sci, 26(1), 97-107. doi: 10.1080/ 02640410701348644.

Welsman, J. R., Armstrong, N., Nevill, A. M., W inter, E. M., \& Kirby, B. J. (1996). Scaling peak V02 for differences in body size. M ed Sci Sports Exerc, 28(2), 259-65. doi: 10.1097/ 00005768-199602000-00016. Young, W. B. , \& Pryor, L. (2007). Relationship between pre - season anthropometric and fitness measures and indicators of playing performance in elite junior Australian Rules football. I Sci M ed Sport, 10(2), 110118. doi: 10.1016/ j.jsams. 2006.06.003.

Zacharogiannis, E. Paradidis, G., \&T ziortzis, S. (2004). An evolution of tests of anaerobic power and capacity. Med Sci Sports Exerc, 36(5), S116. doi: 10.1249/ 00005768-200405001-000549

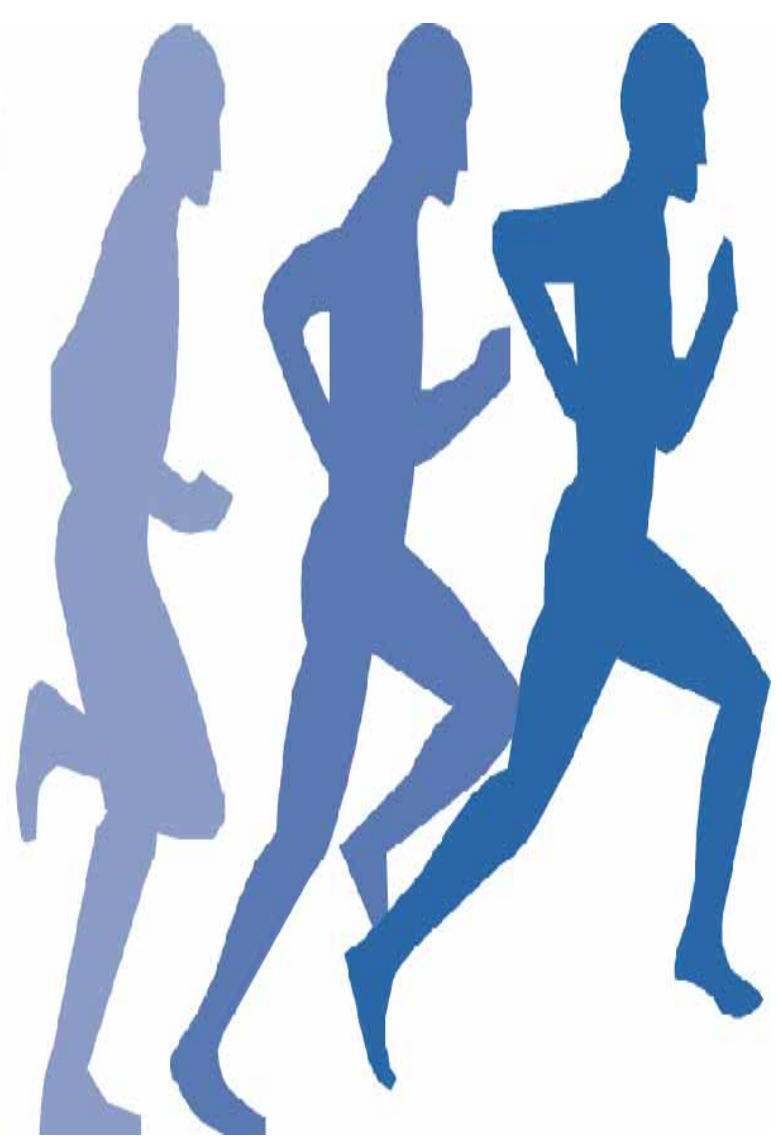

